\title{
Meeting report of the British Society for Gastroenterology Meeting, March 2003
}

\author{
J I W Jones, S I Khakoo
}

Gut 2003;52:1383-1384

T 2003 meeting of the British Society for Gastroenterology (BSG) was held at the ICC Birmingham. The range of subjects covered reflected the diversity of the speciality, and high quality clinical papers were in abundance. This contrasted with an interesting survey showing an apparent decline in the number of publications achieved by SpRs at the time of appointment to consultant grade from a median of 19 in 1993 to only five in 2001. ${ }^{1}$ Our ability to collect large amounts of clinical data are ever improving and current clinical practice came under scrutiny from a number of national and regional surveys. The BSG-blue card surveillance scheme was used to survey mortality from inflammatory bowel disease. ${ }^{2}$ This suggested that these diseases account for about $1 \%$ of all gastrointestinal deaths, and highlighted surgery and sepsis as key factors. The BSG also acted as a conduit for data collection for a national assessment of hepatitis $\mathrm{C}$ care in the UK. ${ }^{3}$ The survey demonstrated regional variation in both healthcare providers and treatment practice, and estimated that only about $5-10 \%$ of hepatitis C virus infected individuals are in secondary care. The theme of service provision was developed in a prospective audit from Scotland of 3293 upper gastrointestinal cancers. ${ }^{4}$ In this series, the provision of services in large specialist centres appear to have little impact on the outcome of the disease. The 53 hospitals surveyed did however experience relatively high mortality rates from both oesophageal $(9-15 \%)$ and gastric (13-15\%) cancers.

The diagnosis of upper gastrointestinal and mediastinal masses was reported to be facilitated by endoscopic ultrasound in combination with fine needle aspiration and trucut biopsy. ${ }^{5}$ Following chemotherapy for oesophageal cancer, however, in one study no single imaging modality (computed tomography, endoscopic ultrasound, positron emission tomography) accurately predicted response to treatment. ${ }^{6}$ In this case prevention is better than cure, and surgery is an alternative to lifelong acid suppression for those with gastrooesophageal reflux. However, a Finnish study demonstrated a 1 in 200 risk of postoperative life threatening or fatal complications in the 11974 patients surveyed. ${ }^{7}$

At the other end, the macroscopic findings of colonoscopy were suggested to have both negative and positive predictive value in the diagnosis of dysplasia in individuals with ulcerative colitis. ${ }^{89}$ This may have implications for both the frequency of colonoscopic surveillance and the sites of sampling for histology. Conversely, when screening for colorectal polyps, severely dysplastic flat adenomas may require indigo carmine spray for accurate diagnosis and are frequently $(95 \%)$ out of reach of the flexible sigmoidoscope. ${ }^{10}$ The "bottom-up" model of colorectal adenoma morphogenesis was supported by the finding of very early adenomatous change involving entire crypts. In this elegant study, tissue from an $\mathrm{XO} / \mathrm{XY}$ individual was used to demonstrate that there were no instances of $\mathrm{XO}$ or $\mathrm{XY}$ adenomatous tissue migrating down to involve crypts of the other genotype. ${ }^{11}$ The genetic simplicity of this study contrasts with the genetic complexity of inflammatory bowel disease (IBD). In individuals stratified for known genetic variants associated with Crohn's disease
(IBD5 and CARD15/NOD2), a genome wide scan of 228 IBD families suggested yet another susceptibility locus on chromosome $16{ }^{12} \mathrm{~A}$ further layer of complexity is that due to the heterogeneity of these loci and their potential for epistatic interaction. Approximately $10 \%$ of individuals with one of the common CARD15/NOD2 mutations have a further coding mutation which in half of the cases could potentially compromise function of the mature protein. ${ }^{13}$

Despite the advent of novel therapies for IBD, azathioprine is still the subject of interesting research. Susceptibility to azathioprine toxicity is linked to thiopurine methyl transferase (TMPT) deficiency. One group described the successful use of very low $(<5 \%)$ dose azathioprine in two individuals with IBD and absence of TPMT and also, at a dose of $1 \mathrm{mg} / \mathrm{kg}$, in 20 of 26 individuals with low TMPT levels. ${ }^{14} \mathrm{~A}$ pragmatic approach to individuals with normal TMPT levels and azathioprine intolerance using a stepwise reintroduction of therapy was also reported..$^{15}$

Basic science was represented in the liver section, with a mechanistic study of stellate cell apoptosis during recovery from experimental liver fibrosis. ${ }^{16}$ The authors suggested that one of the key steps might be cleavage of $\mathrm{N}$-cadherin by matrix metalloproteinase 2 . Successful recovery from fibrosis is accompanied by hepatocyte regeneration. The origin of these recovering cells could be from stem cells expressing the markers CD90 and CD34. These were shown to differentiate into cells expressing hepatic and biliary cytokeratins. ${ }^{17}$ Clinical practice was also challenged with a recalculation of the variables that define mortality in acute alcoholic hepatitis. ${ }^{18}$ The authors' variables performed better than Maddrey's discriminant function, and we await the prospective validation of their system.

Nutrition is a problem affecting hepatologist and luminal gastroenterologist alike. Simple approaches to access problems can be effective and one group had tackled the common problem of rapid closure of gastrostomy sites following PEG displacement by using relatively cheap vascular dilators to enlarge tracts to facilitate transcutaneous replacement. ${ }^{19}$ Ghrelin is one peptide regulating both appetite and body composition. Based on an interesting dataset, in which plasma ghrelin levels increased following Helicobacter pylori eradication, this was speculatively proposed to link $H$ pylori infection, obesity, and gastro-oesophageal reflux disease. ${ }^{20}$

New tools may be required to unearth novel mechanisms of pathogenesis, and microarray technology was used to study the effects of naproxen on the stomach. Data on about 8000 genes was presented, suggesting that the drug causes apoptosis and may affect DNA integrity and repair. ${ }^{21}$ Finally, we were posed the provocative question of how much are you willing to pay to cure one case of non-ulcer dyspepsia ${ }^{22}$ ? Answers on a postcard please.

Abbreviations: BSG, British Society for Gastroenterology; IBD, inflammatory bowel disease; TMPT, thiopurine methyl transferase. 
.................

\section{Authors' affiliations}

J I W Jones, Division of Gastroenterology, University Hospital, Nottingham NG7 2UH, UK

S I Khakoo, Division of Infection, Inflammation, and Repair,

Southampton General Hospital, Southampton, UK

Correspondence to: Dr S I Khakoo, MRC Clinician Scientist, Division of Infection, Inflammation, and Repair, Mailpoint 811 , Level D South Block, Southampton General Hospital, Tremona Rd, Southampton, Hants SO166YD, UK; sik@soton.ac.uk

Accepted for publication 30 April 2003

\section{REFERENCES}

1 Hopper AD, Atkinson L, Prtak L, et al. Research trends in British Gastroenterology: publication rates in newly appointed NHS consultants over a 9 year period. Gut 2003;52(supp 1):A76.

2 Dolwani S, Hawthorne AB. Mortality caused by inflammatory bowel disease in the UK: a two year survey. Gut 2003;52(supp 1):A12.

3 Parkes J, Bennet-Lloyd B, Roderick W, et al. National needs for assessment of hepatitis C. Gut 2003;52(supp 1):A3.

4 Thompson AM, Park KP. Does size matter, or, where should oesophago-gastric cancer be managed. Gut 2003;52 (supp 1):A2 1 .

5 Pereira SP, Falzon M, Kocjan G, et al. Prospective comparison of endoscopic ultrasound guided $22 \mathrm{G}$ fine needle aspiration (EUS-FNA) with 19G Trucut needle biopsy (EUS-TNB). Gut 2003;52(supp 1):A26.

6 Meenan J, Rankin S, Marx G, et al. The accuracy of EUS, HCT and PET in re-staging of oesophageal cancer following chemotherapy. Gut 2003;52(supp 1):A31.

7 Salo JA, Rantanen TK, Sipponen JT. Life threatening complications in fundoplication: analysis of 11974 patients. Gut 2003;52(supp 1):A19.

8 Rutter MD, Schofield G, Wilkinson KH, et al. Colonoscopic appearances help predict dysplasia risk in ulcerative colitis. Gut 2003;52(supp 1):A4.
9 Rutter MD, Wilkinson KH, Saunders BP. Dysplasia in ulcerative colitis is usually visible at colonoscopy. Gut 2003:52(supp 1):A4

10 Hurlstone DP, Shorthouse AJ, Adam I, et al. Anatomical clustering of type II flat and depressed colorectal lesions: relationship between dysplasia, neoplasia, and morphology subtype. Gut 2003;52(supp 1):A21.

11 Preston S, Wong R, Brittan M, et al. Top down or bottom up morphogenesis of colorectal adenomas: competing management structures in the origins of colorectal neoplasia. Gut 2003;52 (supp 1):A30.

12 van Heel DA, Dechairo BM, Dawson G, et al. Complex genetic interactions revealed in an IBD genome scan stratified by Crohn's disease associated variants. Gut 2003;52(supp 1):A12.

13 King K, Onnie C, Mirza M, et al. Sequence variation in the CARD 15 (NOD2) gene and susceptibility to Crohn's disease. Gut 2003;52(supp 1):A60.

14 Ansari A, Escudier M, Marinaki A, et al. Treatment of zero and intermediate TPMT patiens with a tailored dose of azathioprine. Gut 2003;52(supp 1):A64

15 Green CJ, Mee AS. Re-introduction of azathioprine in previously intolerant patients. Gut 2003;52(supp 1):A63.

16 Murphy F, Waung J, Patel N, et al. Balance of TIMP-1 and MMP-2 determines $\mathrm{N}$ - cadherin cleavage in hepatic stellate cell apoptosis. Gut 2003:52 (supp 1):A2

17 Currie IS, Masson NM, Dundas SR, et al. Isolation and characterisation of human hepatic stem cells in fetal liver. Gut 2003;52(suppl 1):A2.

18 Forrest EH, Evans CD, Murray LS, et al. Predictors of short and medium term mortality in acute alcoholic hepatitis. Gut 2003;52(supp 1):A1.

19 Frenz MB, Siuda G, Mclntyre AS, et al. A simple and safe method of transcutaneous gastrostomy replacement. Gut 2003:52(supp 1):A97.

20 Freshwater D, Randeva HS, O'Hare P, et al. Plasma ghrelin following cure of Helicobacter pylori. Gut 2003;52(supp 1):A17.

21 Smith JA, Rose A, James MW, et al. The effect of naproxen on gene associated with DNA damage and repair in the stomach of healthy volunteers by microarray analysis. Gut 2003;52(supp 1):A18.

22 Moayyedi P, Delaney B. A systemic review and economic analysis of the cost- effectiveness of proton pump inhibitor therapy in non-ulcer dyspepsia. Gut 2003;52(supp 1):A16. 